\title{
From Caribbean to Clementine
}

\section{The road to the stars begins in the ocean depths.}

\section{Stephen Baxter}

$t$ is the year 2020. A near-Earth asteroid, a flying mountain of water ice and organics, is approached by the Clementine, a mining craft from Earth. The asteroid's riches are expected to transform the planet's economy.

As the craft gently nuzzles against coaldark asteroid dust, the pilot signals success to her mission controllers on Earth. This is an astronaut who can navigate through space, manipulate her environment and control complex machinery. But she is no human. She is a member of the species Sepioteuthis sepioidea: a Caribbean reef squid - or rather, a genetically enhanced descendant of natural squid.

Her streamlined, torpedo-shaped body is a rich burnt-orange, mottled black. Winglike fins ripple elegantly alongside the body. Her head is crowned by a beak and surrounded by flipper-like arms, and there are two forward-looking eyes, blue-green rimmed with orange.

Alien eyes. Intelligent.

The notion of squid in space would have seemed fantastic to followers of the first human astronauts. But the logic that had led this first cephalopod pilot from the Caribbean to the Clementine had proven inescapable.

It had been understood for some decades that squid were extremely smart molluscs, functionally equivalent to fish. They were highly efficient predators, able to navigate and hunt in three dimensions. They had arms capable of manipulation, used, for example, during mating. They had senses based on light, scent, taste, touch, sound, gravity, acceleration, perhaps even an electric sense.

Squid spoke to each other. Their hides sparkled with patterns made by sacs of pigment granules surrounded by muscles. But were the signals a true language? Human scientists had been able to isolate a number of cephalopod linguistic components that combined in a simple grammar.

But nobody knew what the squid might talk about. They shoaled for mutual protection, but didn't play or groom, and hunted individually. It wasn't clear why such shortlived, only partially social animals needed such complex communication systems.

Nevertheless, in the early twenty-first century, laterally thinking space scientists realized that cephalopods - in particular the reef squid - could have precisely the toolbox needed to equip them for uses in space.

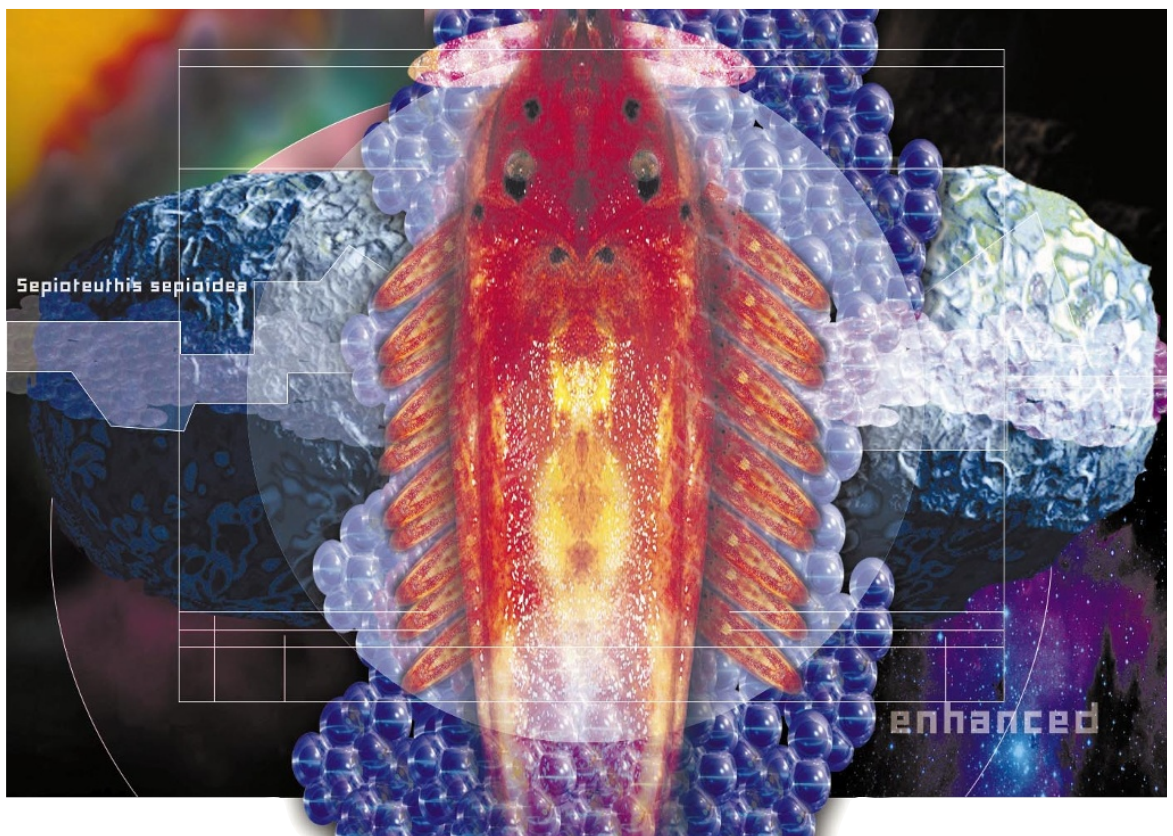

Squid lived in free-fall anyhow, and so were adapted to the gravity-free conditions of space - for them there would be none of the physiological problems that plagued human astronauts. Their lifesupport requirements were simple: a bubble of water with a basic oceanic ecosystem would suffice. They could navigate with their powerful, predators' eyes. They could communicate. And they could manipulate their environment.

A major international project - funded by NASA, ESA and various oceanographic institutes - was initiated. Its goal was nothing less than to enhance the intelligence of reef squid.

It was a major technical challenge. A squid's neural layout is not like that of a human. A squid has two nerve cords running like rail tracks the length of the body, studded with pairs of ganglia; the most anterior pair of ganglia are expanded into a mass of lobes. The scientists quickly identified the areas of the brain responsible for language learning (unpleasantly, by cutting away parts of squid brains to see what happened.) It was discovered that some comparatively simple genetic engineering could be deployed to make squid smart — or rather, smarter.

There were protests, of course, from animal-rights activists: but also anguish of a more philosophical kind, from groups that questioned the ethics of our ability to inflict an awareness of mortality on another creature not previously sentient.

Despite such opposition, and also the crises, the uplifting effort produced rapid results. Soon, enhanced squid were performing useful work in the ocean - working on sea farms, for example. And the first experiments were performed to see if they could operate outside the Earth altogether.

To no one's great surprise, they made fine astronauts.

Eerily, as some pointed out, it was almost as if the squid had evolved for the conditions of space travel - as humans self-evidently hadn't. Some conspiracy theorists began to wonder if the primary purpose of humanity had been, all along, to deliver enhanced cephalopods to their natural environment in space. And others, wary of the squid's huge potential, began anxiously to watch the skies.

She can feel the feather-touch of new gravity. Beneath the translucent skin of her habitat she can see a grainy, grey-black ground, a jagged horizon, barely tens of metres away. Earth is very remote, and her ties of loyalty to humanity are stretched. To the squid pilot, the warmth in her mantle cavity - impregnated eggs - is much more important.

And to her, this asteroid is no mine in the sky. It is a breeding ground. She flashes her triumph, her mantle skin tingling. At last, with a sense of excitement, she slips her arms into the waldoes and prepares to begin her work.

Stephen Baxter writes science fiction that is extrapolated from current understanding. His latest novel is Time (HarperCollins). predictable funding 